\title{
Geospatial Information as a Tool for Soil Resource Information, Management and Decision Support in Nigeria
}

\author{
ADEDEJI, OLUDARE H \\ Department of Environmental Management and Toxicology, Federal University of Agriculture, PMB 2240, Abeokuta, Nigeria \\ *Email: adedejioh@funaab.edu.ng
}

\begin{abstract}
Understanding and addressing the complexity of soil resources management and factors involved requires collection and interpretation of relevant data that will serve as decision support tools. Geospatial information is a veritable tool for soil resource information and decision support for soil management, which is yet to be well embraced in Nigeria. This paper emphasized the importance of geospatial information as a decision support tool to make better and informed decision in the management of soil resources. It also reviewed and discussed status of soil information systems and need to promote strategies for sustainable soil resource development in the country.
\end{abstract}

\section{DOI:https://dx.doi.org/10.4314/jasem.v23i12.5}

Copyright: Copyright (C) 2019 Adedeji. This is an open access article distributed under the Creative Commons Attribution License (CCL), which permits unrestricted use, distribution, and reproduction in any medium, provided the original work is properly cited.

Dates: Received: 11 October 2019; Revised: 10 December 2019; Accepted: 21 December 2019

Keywords: Soil information system, Decision support system, remote sensing, digital soil mapping

The soils of the world are major contributors to ecosystem services such as food production, climate regulation and mitigation, carbon sequestration, issues of biodiversity, land degradation, water quality and quantity and energy issues(Zinck, 2013; Hempel et al., 2014). The soil isan environmental medium that is often neglected because people sometimes do not realize the importance it has for the ecosystem and the economy (Nkwunonwo and Okeke, 2013). Soil resources all over the world are faced by many constraints such as soil erosion, salinization, flooding, declining fertility, desert encroachment, mismanagement and general misuse that hamper its productivity. The major drivers are the unprecedented growth in human population and wasteful consumption pattern in different parts of the world (Geymen and Baz, 2008). Despite these problems however, there is inadequate information on the extent and control of environmental degradation issues including soil erosion, soil nutrient depletion and soil degradation (Mulaku, 2002; Abdallah et al., 2019) especially in developing countries. In Nigeria like many other developing countries, information on the nature, distribution, values as well as appropriate management techniques of the soil resources are still poor. Even when information is available, it is frequently inappropriate or difficult to access and mobilize in order to support decision making in natural resource management. This issue has elevated the need for higher quality, more consistent and more relevant soil information across the world (Pásztor et al., 2012; Hempel et al., 2014). As one of the main concerns of Agenda 21 is the availability of reliable, geographically specific information on natural resources and the environment (Clarke et al., 1999), there has been growing demand for soil information to strengthen green economy initiatives and community adaptation strategies to climate change (Levin, 2013). Spatial information, while readily available in industrialized countries, is often incomplete or outdated and thus not compatible with modern management requirements in developing countries. To meet the challenges of achieving appropriate balance between the use of natural resources and the maintenance of an optimal natural environment; there is the need for adequate information (spatially referenced or geospatial information) on the earth's processes. Soil survey provides an accurate and scientific inventory of different soils, their kind and nature, and extent of distribution so that one can make prediction about their characters and potentialities (FAO, 1996). This will assist in making informed decisions for the management of the soil resources and for planning sustainable land management and decision-making. Soil information is needed for diverse requirements such as scientific diagnosis of soil; establish the potentials and limitations, optimal land use planning, monitoring problem soils and degradation, basis for transfer of technology and aid in decision-making (Elmira, 2012; Ogunbadewa, 2012). Soil resources inventory provides an insight into the potentialities and limitation of soil or its effective exploitation and an accurate knowledge of land use and land cover features represents the foundation for 
land classification and management (Dai and Khoraran, 1998). Access to spatial information on important resources such as the soil by policy makers and administrators, is important for the sustainable socio-economic development of a nation. This is reflected in the growing interest in the concept of spatial data infrastructure (SDI) at the national and global levels. Geographical information systems (GIS) integrated with remote sensing can be used to identify areas of land degradation and link them to physiographic settings (Van Lynden and Mantel, 2001; Gao 2008a,b). The availability of earth observation (EO) data in hard copy as well as digital format have resulted in a plethora of applications such as its use in agricultural landscape mapping, soil classification, soil analysis and soil moisture assessment (Hrishkish, 2012; Bui et al., 2016). Developing countries such as Nigeria are faced with the problem of the lack of capacity for the development of such infrastructures in order to optimize their limited resources. Although geospatial data on soil now exist in different forms in Nigeria, these are largely house in different government departments and research institutions without any form of coordination (Adeniyi, 1992; Okeke and Nkwunonwo, 2007; Nonguierma, 2011).Moreover relevant information for planning purposes remains scare due to absence of a national spatial data infrastructure despite the variety of research on different aspects of soil resources. Efforts at thematic mapping has increased in recent year as the result of advances in geographic information and remote sensing techniques but mapping of soil types and characteristics has not fully shared in this advancement especially in developing country like Nigeria, because of the complexity of soil geography and the high cost of its direct observation (Ismail and Yacoub, 2012).This makes it difficult to have reliable information and make better decisions on the soil resources. Nigeria like most countries in sub-Saharan Africa is faced with challenges to put in place policies, resources and structures to make available geographic information especially as it relates to management of land resources such as soil (Nonguierma, 2011). Until recently, these countries relied solely on the traditional method of collecting soil such as, drainage, ecology, mapping units, classification type, texture, $\mathrm{pH}$ values, unique locations, and landscape, using qualitative methods. Such methods are however considered slow, time consuming and expensive (Lark, 2007) and the resulting soil maps often suffer from dimensional instability, with highly generalized legend, nonflexibility of scale (Okeke and Nkwunonwo, 2007; Bui et al., 2016). The maps tend not to be suitable for quantitative purposes (Zhu et al., 1997) thus the need for a reliable and quantifiable soil information system that offers the opportunity for quick, quantitative, upto-date, high resolution and more accurate soil data (Nkwunonwo and Okeke, 2013; de Sousa Lima et al., 2014).Soil survey is characterized the mapping of soil units in such a way that useful statements can be made about their land use potential and response to changes in management. Therefore, digital soil mapping (DSM) refers to techniques of mapping soils with mostly digital techniques by incorporating field (and traditional legacy soil information). The idea is to make soil survey, classification, and land evaluation as objective as possible. Thus this paper reviewed and discussed status of soil information systems and need to promote strategies for sustainable soil resource development in Nigeria. It emphasized the importance of geospatial information as a decision support tool to make better and informed decision in the management of soil resources.

Soil resource mapping in Nigeria: The soil is a fundament resource for the development of any country, however, in Nigeria; implementation of geospatial data infrastructure as a decision support system for various natural resources and environmental applications has not been well developed (Ogunbadewa, 2012). The country is faced with a myriad of problems ranging from lack of accurate, up-to-date and quantitative soil data, which have resulted in continuous misuse and degradation of soil resources. In addition, the high degree of spatial or temporal variability in the tropics has long been recognized and this has made it difficult for most tropical soils to be mapped and predict accurately their management and productive potentials (Ogunkunle, 2003; Akinbola et al., 2010; Egbuchua, 2014). Concerning soil mapping in Nigeria, existing information on soil resources are compiled on a national basis and were mostly based on coarse spatial resolution satellite remote sensing data plus small scale map covering very large areas but with very little details. Until recently, no systematic soil survey, soil classification and land use capability of the country, have been carried out (Asekunowo, 2009). The country still maintains the conventional soil maps, and serious attempts have not been made at reverting to digital soil mapping. The first provisional soil map of Nigeria was published by Survey Department, Lagos in 1952. The publication of the CCTA soil map of Africa (FAO, 1964) and FAO Soil Map of the World (FAO-UNESCO, 1974) followed this. It was not until the late 1970s that the Federal Department of Agricultural Land Resources, with assistance from USDA initiated a national soil inventory project to produce "a systematic and correlated soil map of the country which would provide a good guide for agriculture and other land development" (FDALR, 
1990). Most of the available soil maps are in prints and out-dated which has been criticized for being time consuming and costly and in response to these criticisms, new approaches have been proposed and developed to improve the mapping of soils and their attributes (McBratney and Lagacherie, 2007;McBratneyet al.2003; Iwashita et al., 2012; Lima, 2013). The most recent national soil map, at the scale of 1:3,000,000, was compiled by Sonneveld (1996) from the pre-1985 soil maps. Basically, the country lacked spatial data infrastructure (SDI) as regard to the soil resources which affects the ability for better decision-making in the management and development of this vital natural resource. While the concept of integrated geospatial infrastructure is well accepted with numerous advantages, its execution in Nigeria is riddled with a number of challenges such as: Financial resources mobilization;Lack of adequate impetus to set up such infrastructure; Arousing political interest among decision-makers and policymakers; and Lack of standardization as the level of standardization is presently very low.

Presently, the challenge is how to captured and transformed into databases that may be used for temporal trend analysis and for a digital soil mapping (DSM)programme the hundreds of soil surveys at various scales, ranging from farm levels to national scale. Digital soil mapping is a predictive approach to model soil spatial variation based on the relationship between soil and its environmental conditions (Zhu et al., 2001; McBratney et al., 2003).

A digital soil map is a spatial database of soil properties that is based on a statistical sample of landscapes or regions, which permits functional interpretation, spatial prediction, and mapping of soil properties relevant to soil management and policy decisions (Lagacherie et al., 2006; 2007; Lagacherie and McBratney, 2007). However, there is the inadequacy or a lack of georeferencing of soil records and the inconsistency in the laboratory and mapping methods, taxonomy, legends, soil survey reports and the deterioration of paper hardcopy soil maps. Furthermore, most available geospatial data collecting agencies have few digital management systems for data capture and processing, their locations are scattered in different parts of the country, while available datasets are scanty and expensive. There is the need to capture and rejuvenate the relevant legacy soils data for Nigeria in digital form to disseminate soil information more easily and for quick and proper decision-making (Dent and Ahmed, 1995; Rossiter, 2008). Digital soil mapping (DSM) involves the creation of spatial soil information systems using field and laboratory methods coupled with spatial and non- spatial soil inference systems. An important aspect of the rejuvenation of historical soil data is data renewal or data resurrection (Dent and Ahmed, 1995), which entails the transformation of the rescued data into usable digital (GIS) formats (Rossiter, 2008). Data rescue involving scanning of the historical records and storing them in appropriate, easily accessible media such as DVD or Web publications. Data rescue also include the collection and input of metadata that describe the source and nature of the rescued data (report, map, database, legend) and the approximate extent and geographic location of the data (Rossiter, 2008).DSM is focused on soil attributes, assuming that these are continuously varying in space and quantitative models developed within GIS environment are used to describe, classify and study the spatial distribution patterns of soil as it occurs in the field. It is a way to bridge the gap in scales between ground-based soil monitoring activities, which are normally limited to the point or small scales and modelling activities thatcover larger areas. A step further to this would be to combine remotely sensed soil-related information with proximally sensed and traditionally measured soil property data at larger spatial scales (Werban et al., 2013). Maps generated using DSM may be adequate for extrapolating soil distribution information to areas where no comprehensive soil map is available (Abdel-Kader, 2011). Nigeria as the giant of Africa launched the NigeriaSat-2, NigeriaSat-X (Earth Observation Satellites) and NigComSat-1R (a communication satellite) in to the space orbit in August and December 2011 respectively, which will serve as a boost to our National security if well explored. Nigeria Sat-2 was launched in August 2011. It is high resolution satellite spatial resolutions of $2.5 \mathrm{~m}$ panchromatic and $5 \mathrm{~m}$ multispectral and with area coverage (swath width) 600 by $600 \mathrm{~km}$ with the ability to rapidly produce accurate mapping to updates the existing information and acquiring new mapping information. It is has the Red, Green, Blue and Near -infrared band. The Nigeria Sat-2 allows for infrastructure mapping, settlement classification, development of urban green spaces, service provision maps, and access control mechanisms regional planning, security, environmental and disaster management. NigeriaSatX was launched in August 2011 alongside NigeriaSat1. It was designed and built by Nigerian Engineers in the UK. It is a medium resolution satellite with a resolution of $22 \mathrm{~m}$ multispectral. . It is has the Red, Green and Near -infrared band with a swath width of $700 \mathrm{~km}$. NigComSat-1R is a replacement satellite for NigComSat-1 Satellite.

Geospatial Technology for Soil Resources Management: According to Buhren and Decker 
(2008), all planning and management activities require information. However, there are challenges which include how to determine what data and information is needed, find out if this already exists, how to get hold of it if it exists, and how to collect it if it does not. In addition there is the need to determine how to store this information in easily accessible and referenced form, how to interpret the data, resolve questions of quality, contradictions and incompleteness; (f) how to determine who needs the information, when and in what form(s); and ( $\mathrm{g}$ ) how to disseminate it as required. Given the fact that existing mapping tools in Nigeria and many other developing countries are failing to provide accurate enough information on the natural resources such as the soil, there is the need for the adoption of existing advance technologies to tackle these problems. In the past two decades much changes and developments in technologies and trends have brought new challenges and opportunities in GIS domain. GIS have been moving towards an era in which the power of such systems is continuously increasing in multiple facets consisting of computing, visualizing, mining, reasoning data (Pourabbas, 2014). For instance, the establishment of the Open GIS Consortium is aimed at developing publicly available geoprocessing specifications. Geospatial technologiescan make a huge difference in the availability and cost of geospatial data thus making them readily available to variety of users. These technologies now collect multipurpose data simultaneously, which has different horizontal applications because they record 'everything in their way' (Killpack, 2011). These include the LiDAR, digital video, multi-spectral and hyperspectral sensors and real-time sensors on farm and construction implements. Multispectral and hyperspectral sensors collect all of the bands at once and the data is spatially and time co-registered, user has access to a robust quantity of valuable information for the same spatial area at the exact time increment (Collado et al., 2002; Killpack, 2011).Geospatial technology has many important roles in sustainable development and management of soil resources. Spatial tools such as the global positioning system (GPS) and geographic information systems (GIS) for storing and analyzing spatial data can help make better decisions in agriculture, land development, and environmental protection and restoration.

Mapping of soil properties is very important because it plays an crucial role in the knowledge about soil properties and how it can be used sustainably (Hengl, 2007a).Creation of a standard soil geospatial database will ensure consistent access, availability, and performance and promotes data sharing and coordination. Individuals, agencies and organizations can readily access digital base data, digital aerial photography and high resolution satellite imagery from other government departments and nongovernment organizations. Geospatial database is dynamic in nature and can be continually updated by data collection staff. The information derived is useful to individuals, farmers, environmental planners and government agencies for environmental farm planning, nutrient management planning, and decision-making processes.

Digital soil mapping(DSM) can make use of large legacy of soil data in the form of soil maps, soil survey reports, soil profile descriptions, or antiquated card catalogue collected by past generations of soil surveyors (Mayr et al., 2008). The old soil data is not only for soil information preservation (Rossiter, 2008) but also serve as the only source of meaningful soil information for Digital Soil Mapping (DSM) in many of data-scarce countries of the developing world (Odeh et al., 2012).The Food and Agricultural Organization (FAO) has soils dataset originally published in 1974 as the Soil Map of the World (SMW), first digitized by Environmental Systems Resources Institute (ESRI) in 1984 in vector format; and later re-projected and converted to grid format by the Global Resources Information Database (GRID) project of the United Nations Environmental Programme. Presently, the Digital Soil Map of the World (DSM) includesnearly 5000 mapping units and more than 200 soil-units (scale 1:5,000,000). The Digital Soil Map of the World (DSMW) consists of ten map sheets: Africa, North America, Central America, Europe, Central and Northeast Asia, Far East, Southeast Asia, and Oceania (FAO/AT2010, 1995.). It was compiled from individual country soils data, which used a variety of local soils data, and is a generalization of those data. Country boundaries have been updated as of 1994 at 1:3,000,000 scale (FAO/UNESCO, 2003). The DSMW contains two types of files: map files and derived soil properties files. The map files are available in three GIS formats: one vector format (ARC/INFO Export) and two raster (scale 5 x 5 arc-minute) formats: ERDAS and IDRISI. The Derived Soil Properties files consist of interpretation programs and related data files. The programs are written in QuickBasic and can be read using DOS or OS/2 operating system. Programs are included that interpret the maps in terms of agronomic and environmental parameters (e.g. $\mathrm{pH}$, organic carbon content, $\mathrm{C} / \mathrm{N}$ ratio, clay mineralogy, soil depth, soil and terrain suitability for specific crop production, soil moisture storage capacity and soil drainage class). The programmes produce analyses of soil inventories, problem soils and fertility capability classification. Included are maps of soil units classified according to 
the World Soil Reference Base and topsoil distribution, which can used in teaching soil science. The database includes information on soil moisture storage capacity, soil drainage class and effective soil depth, useful for environmental studies. Recently, the first version of the Africa Soil Profiles Database was released by ISRIC - World Soil Information as a contribution to the production of high-resolution soil property maps for Sub Saharan Africa. Version 1.1 of this georeferenced and standardized legacy soil profile database for Sub Saharan Africa contains over 12,000 records for 37 countries, compiled from over 300 data sources. Data were converted to a common standard, parsed through basic quality rules, and cleaning. This inventory of legacy soil maps of Sub Saharan Africa draws from international holdings at ISRIC (Wageningen), FAO (Rome), IRD (Montpellier), WOSSAC (Cranfield), JRC (Ispra), Ghent University, and national holdings at Mlingano (Tanzania), Sotuba (Mali) and Zaria (Nigeria). Currently, some 5000 maps are included in the database and these cover the continent at different scales, using different legends.

Applications of Geospatial Information Soil Resource Management and Decision Support: The determination of the long-term trend of land degradation requires spatial comparison of multiple land cover maps derived from remotely sensed data at different times (Geymen and Baz, 2008). Lo and Yeung (2002) note that a major facet of this current era is the development of the geographic information infrastructure. Such infrastructure could be used to support various decision-making processes in urban planning, engineering and environmental resource management. Spatial data management including data storage and data exchange (between several project sections) is particular important for interdisciplinary research projects which focus on environmental field studies and regional modelling (Mückschel and Nieschulze 2004). Optimal soil management and environmental protection require agricultural and natural resource managers equipped to characterize and manage soil spatial variability. Werban et al. (2013) posited that in the face of the new challenges in the context of climate and global change and the increasing need of multidisciplinary, a more sophisticated use of soil information beyond the "classical" soil information is needed. Predictive soil mapping (Scull et al., 2003) or digital soil function mapping are promising ways to enhance the information content of soil maps (Ismail and Yacoub, 2012).Among the many predictive digital soilmapping approaches, SoLIM (soil land inference model) is one of the few digital soil mapping approaches that can be used in the production of soil surveys (Zhu et al., 2001). The SoLIM couples
GIS/remote sensing techniques with artificial intelligence techniques to map spatial distributions of soil characteristics using fuzzy logic. The integrating role of GIS in environmental analysis system and the tradition of using metadata and geospatial data standards in GIS make tracking scaling steps much easier.

With the rapid development of remote sensing and geoinformation science, natural resources survey teams are now increasingly creating their products (geoinformation) using ancillary data sources and computer programs - the so-called direct-to-digital approach (Hartemink et al., 2008; Hengl, 2007a,b; Pásztor et al., 2012). In digital soil mapping, soil variables such as $\mathrm{pH}$, clay content or concentration of a heavy metal, are increasingly mapped using the regression-kriging framework: the deterministic part of variation is dealt with maps of soil forming factors (climatic, relief-based and geological factors) and the residuals are dealt with kriging (McBratney et al., 2003). Geospatial reasoning creates the objective connection between a geospatial problem representation and geospatial evidence. According to Aderoju et al (2013), one set of activities, information foraging, focuses around finding information while another set of activities, sense making, focuses on giving meaning to the information. This information, coupled with other measurements and field scouting information, allows for effective application of sitespecific management practices (Mark and Waddington, 1997). Retrieval of biophysical variables from satellite time series should result in a quantitative description of the land surface in all dimensions (Defourny and Bontemps, 2012). For instance, LIDAR digital elevation data is used to help farmers better manage their fields. Furthermore, soil moisture is an important component of the terrestrial environment that significantly regulates water circulation and surface energy exchanges between land surface and the atmosphere (Vereecken et al. 2014; Umar et al., 2017). Estimation of soil moisture is crucial to improve the forecasting of precipitation, temperature, droughts, and floods (Albergel et al. 2013). Active remote sensors such as longer-wavelength microwave have excelled quite at measuring soil moisture (Njoku et al., 2002). They could effectively be used to estimate soil moisture near the surface of the earth (Santos et al. 2014) because it could penetrate thick vegetation cover and appropriately sense the soil moisture. Soil moisture estimation can be done across varying spatial and temporal scales (Singh et al. 2005, Umaret al., 2017).

In the United States of America, a National Spatial Data Infrastructure was established in 1994 with a 
remit to enhance technological, political, standards and human resource aspects of GIS through acquiring, processing, sharing, distributing and improving the utilization of geographic data.Remote sensing provides significant source for real-time and accurate data related to land and soil. It enables homogeneous information over large regions, and can therefore greatly contribute to regional erosion assessment (Siakeu and Oguchi, 2000). Mobile phone application such as SOILWEB APP for smart phones is an easyto-use suite of web based mapping tools that allow users to interact with soil survey via Google Earth, Google Maps, and an original standalone interface (Beaudette and O'Geen, 2009, 2010). The technology has revolutionized the use of digital soil survey information, allowing users to access soils information in the field where it is often most needed and to apply decision support tools directly to the customer in real time (Hartemink et al., 2008; Levin, 2013). In 2008, a group of scientists led by Dr. Sanchez worked to develop a proposal to the Bill and Melinda Gates Foundation and the Alliance for a Green Revolution in Africa (AGRA) called AfSIS-African Soil Information Service. AfSIS as a major step towards a digital soil map of the world. Although focused on Sub Saharan Africa, the Gates Foundation had the wisdom to allocate about $10 \%$ of the funding to develop the GlobaSoilMap.net Consortium.As an account for seasonal variability, multi-temporal satellite images are useful to extract the valuable information associated to seasonal land use dynamics for mapping land use/land cover (De Bie, 2005). Remote sensing in combination with ancillary information and spatial models in a geographic information system environment would yield reliable results concerning inventories of natural resource and environmental monitoring. (Singh et al., 2002; Lillesand et al., 2007; Neumann et al., 2012; Pretorius, 2013).Finke (2012) indicated the potential of integration of sensors in making maps and providing model input. Furthermore, Krüger et al. (2013) combined results of geophysical sensor data for extraction of high resolution soil depth information to enhance accuracy of biomass modelling, while Ugbaje and Reuter (2013) present an approach to apply DSM procedures to predict available water capacity of soils in Nigeria using pedotransfer functions (PTFs).

Conclusion: Continuous environmental degradation and critical issues such as soil erosion in Nigeria calls for a way development of policy tools and mechanisms for appropriate land use management, involvingthe stakeholders in the decision making process. Therefore, the need to improve data quality and efficiently handle large amount of data by using modern information gathering techniques to produce up-to-date information. This will facilitate the decision making process in different applications including soil resource management and sustainable development

\section{REFERENCES}

Abdel-Kader, FH. (2011). Digital soil mapping at pilot sites in the northwest coast of Egypt: A multinomial logistic regression approach. The Egyptian Journal of Remote Sensing and Space Sciences 14:29-40

Abdallah, S; AbdElmohemen, M; Hemdan, S; Ibrahem, K (2019). Land Assessment for Agricultural Use in Jizan Basin, KSA, After 48 Years of Jizan Dam Construction. Journal of the Indian Society of Remote Sensing https://doi.org/10.1007/s12524-019-01038-x (0123456789().,-volV)(01234567891V)

Adeniyi, PO (1992). Space Technology for Resource Management for Suitable Development inNigeria. University of Lagos, Lagos, Nigeria: University of Lagos Press.

Aderoju, O M; Onuoha, HU; Ibrahim, M (2013). Optimization of Nigerian Satellites and GeoSpatial Intelligence on National Security. $J$. Environ. Sci. Toxic. Food Technol. 7, (4) 23192402

Akinbola, GE; Ojo, UA; Adigun, MO (2010). Variability of properties of some pedons on basement complex of South Western Nigeria. Proceedings of the 34th Annual Conference of the Soil Science Society of Nigeria 22nd - 26th March, 2010, Ibadan, Nigeria.

Albergel, C; Dorigo, W; Balsamo, G; Muñoz-Sabater, J; de Rosnay, P; Isaksen, L; Wagner, W (2013). Monitoring multi-decadal satellite earth observation of soil moisture products through land surface reanalyses. Remote Sensing of Environment, 138:77-89.

Asekunowo, V.O (2009). An Appraisal of Fertilizer Subsidy in Developing Countries. Nigerian Journal of Soil Science 2009 Vol. 19 No. 2 pp. 3243. Retrieved from http://www.cabdirect.org/abstracts/20011310982 0. hmtl. Accessed on $15^{\text {th }}$ June, 2011.

Beaudette, D; O’Geen, AT. (2009). Soil-Web: An online soil survey for California, Arizona and Nevada. Comput. Geosci. 35:2119-2128. 
Beaudette, D; O'Geen, AT (2010). An iPhone application for on demand access to digitalsoil survey information. Soil Sci. Soc. Am. J. 74:16821684.

Bui, E (2016). A Review of Digital Soil Mapping in Australia. In: Lagacherie, A.B. McBratney and M. Voltz (Editors). Developments in Soil Science, volume $31 \mathrm{P}$.

Clarke, D; Holland, P; Nairn, A; Swift, A; Robertson, D (1999). The contribution of the Global Map to a GSDI. Available at: http://www.gsdidocs.org/docs 1999/globalmap.html [Accessed 30, June 2014]

Collado, AD; Chuvieco, E; Camarasa, A (2002). Satellite remote sensing analysis to monitor desertification processes in the crop-rangeland boundary of Argentina. Journal of Arid Environments 52:121-133

Dai, X; Khoraran, S (1998). A hierachicalmethodology framework for multisource data fusion in vegetation classification. Int.Journal of Remote Sensing 19(18): 3697-3701.

de Sousa Lima, LA; Reatto, A; Roig, HL (2014). Soil Mapping of a Small Watershed in a Brazilian Savanna Biome: A Semi-Automatic Approach. Journal of Geographic Information System, 6: 7987.

De-Bie, CAJM (2005) Assessment of soil erosion indicators for maize-based agro-ecosystems in Kenya. Catena 59:231-251.

Defourny, P; Bontemps, S (2012). Revisiting landcover mapping concepts, in Giri, C.P. (Ed). Remote sensing of land use and land cover. Taylor \& Francis Group. Boca Raton, FL

Dent, DL; Ahmed, FB (1995). Resurrection of soil surveys: a case study of the acid sulphate soils of The Gambia. I. Data validation, taxonomy and mapping units. Soil Use and Management 11:6976.

Egbuchua, C.N. 2014. Variability in Soil Properties as Influenced by Different Land Use Types in an Ultisols of the Tropical Region, Delta State, Nigeria. Agricultura TropicaetSubtropica, 47(2): 43-48. DOI: 10.2478/ats-2014-0006

Elmira, Y (2012). Application of GIS for processing of soil data. Korkyt Ata Kyzylorda State University. Szekesfehervar 2012
FAO, (1996). Guidelines: Agro-ecological Zoning. Food and Agricultural Organization, Soils Bulletin, Rome, Italy. Available at: http://www.wamis.org/agm/pubs/agm8.com. [Accessed 30, June 2014]

FAO/AT2010(1995). World Agriculture: Towards 2010, An FAO Study. Edited by N.

Alexandratos. Published by FAO and J. Wiley\& Sons, 1995. FAO/UNESCO (2003). Digital Soil Map of the World and Derived Soil Properties, CD-ROM, Version 3.6. Information Division, FAO, Viale delle Terme di Caracalla, 00100 Rome, Italy,

FDALR (1990). Soil map of Nigeria. Federal Department of Agricultural Land Resources, Kaduna, Kaduna State Nigeria.

Finke, PA (2012). On digital soil assessment with models and the pedometrics agenda. Geoderma 171-172:3-15. doi:10.1016/j.geoderma.2011.01.001

Gao, J (2008a). Mapping of land degradation from ASTER data: a comparison of object-based and pixel-based methods. GIS Science and Remote Sensing 45 (2):149-166

Gao, J. ( 2008b). Detection of changes in land degradation in Northeast China from Landsat TM and ASTER data. In: Proceedings of the XXIth Congress of ISPRS. Beijing, China, 3-12 July (CD-ROM).

Geymen, A; Baz, I (2008). The potential of remote sensing for monitoring land cover changes and effects on physical geography in the area of Kayisdagi Mountain and its surroundings (Istanbul). Environmental Monitoring and Assessment 140(1-3): 33-42.

Hartemink, AE; McBratney, AB; Mendonça-Santos, ML (Eds.). (2008). Digital Soil Mapping with Limited Data Springer, New York

Hempel, JW; McBratney, AB; Arrouays, D; McKenzie, NJ; Hartemink, AE (2014). GlobalSoilMap Project History

Hengl, T (2007a). A Practical Guide to Geostatistical Mapping of Environmental Variables. European Commission. Joint Research Centre. Institute for Environment and Sustainability. EUR 22904 EN http://ies.jrc.ec.europa.eu 
Hengl, T ; Toomanian, N ; Reuter, H I ; Malakouti, MJ (2007b). Methods to interpolate soil categorical variables from profile observations: lessons from Iran. Geoderma, 140 (4): 417-427.

Hrishkish, S (2012). Here, There and Everywhere. In: Dasgupta, A (Managing Editor, Geospatial World). Vol.2 Issue 6, January 2012.

Ismail, M. and Yacoub, R.K. (2012). Digital soil map using the capability of new technology in Sugar Beet Area, Nubariya, Egypt. The Egyptian Journal of Remote Sensing and Space Sciences 15: 113-124

Iwashita, F., Friedel, M.J., Ribeiro, G.F. and Fraser, S.J. (2012) Intelligent Estimation of Spatially Distributed Soil Physical Properties. Geoderma, 170:1-10.

Killpack, C (2011). Big Data, Bigger Opportunity. In: Geospatial Content Geospatial World. April 2011

Krüger, J; Franko, U; Fank, J; Stelzl, E; Dietrich, P; Pohle, M; Werban, U (2013). Linking geophysics and soil function modelling-An application study for biomass production. Vadose Zone J. 12 . doi:10.2136/vzj2013.01.0015

Lagacherie, I P; Bratney, MC; Voltz, IJ (2006). Map Soil Conditions, Set a Baseline forMonitoring Changes, and Provide Options for Soil and Land Management: African SoilInformation System (AFSIS).Available at: http://www.africasoils.net/about/rationale. [Accessed30, June 2014]

Lagacherie, P; McBratney, AB (2007). Chapter 1. Spatial soil information systems and spatial soil inference systems: perspectives for Digital Soil Mapping. In: P. Lagacherie, A.B. McBratney and M. Voltz (Editors), Digital Soil Mapping: An Introductory Perspective. Developments inSoil Science, volume 31. Elsevier, Amsterdam, pp. 3 24.

Lark, M (2007), Background to Digital Soil Mapping. International Working group on Digital Soil Mapping Commission 1.5 Pedometrics. Rothamsted Research, Harpenden Hertfordshire, United Kingdom.

Levin, MJ (2013). Green Economy and Infrastructure Contributions of USDA Urban and Nonfarm Soil Projects in the U.S. Soil Horizons, doi: 10.2136/sh2013-54-5-gc. Soil Science Society of America. Open access.

Lillesand, T; Kiefer, RW; Chipman, J (2007). Remote sensing and image interpretation (6th $E d)$. Chichester, UK, Wiley.

Lima, LAS (2013) Aplicação dos Métodos SemiAutomático e LógicaFuzzy para o Mapeamento Pedológico da Bacia do Sarandi. Master's Thesis, University of Brasília, Brasília.

Lo, CP; Yeung, AKW (2002). Concepts and techniques of geographic information systems. Upper Saddle River, USA, Prentice Hall.

Mark, WB; Waddington, GR (1997). Utility of Spatially Related Data for Managing Agricultural Variety. Environmental System Research Institute. Retrieved from http://www.proceedings.esri.com. [Accessed 30, June 2018]

Mayr, TR; Palmer, RC; Cooke, HJ (2008). Digital Soil Mapping using Legacy Data in the Eden Valley, UK. In: A.E. Hartemink, A. McBratney\& M.L. Mendonça-Santos (Editors), Digital Soil Mapping with Limited Data. Springer, pp. 291-301.

McBratney, AB; Lagacherie, P (2007). Spatial soil information systems and spatial soil inference systems: perspectives for digital soil mapping. In: Lagacherie P., A.B. McBratney \& M. Voltz (eds.) Digital Soil Mapping. Elsevier, Amsterdam: pp. 3-22.

McBratney, AB; Mendonça Santos, ML Minasny, B (2003). On Digital Soil Mapping. Geoderma, 117, $3-52$.

Mückschel, C; Nieschulze, J (2004). Editorial zumSchwerpunktthemadieserAusgabe:

Datenmanagement in interdisziplinärenUmweltForschungsprojekten.

ZeitschriftfürAgrarinformatik, Heft 4, p. 68.

Mulaku, GC (2002). The concept of Spatial Data Infrastructure: An African Perspective. Geospatial Today. May - June 2002, 13-19

Neumann, MRB; Roig, HL; Souza, ALF (2012). Digital Elevation Models Obtained by Contour Lines and SRTM/Topodata, for Digital Soil Mapping. Journal of Soil Science and Environmental Management, 3:104-109. 
Njoku, EG; Wilson, WJ; Yueh, SH; Dinardo, SJ; Li, FK; Jackson, TJ; Lakshmi, V; Bolten, J (2002). Observations of soil moisture using a passive and active low-frequency microwave airborne sensor during SGP99. IEEE Transactions on Geoscience and Remote Sensing, 40(12):2659-2673.

Nkwunonwo, UC; Okeke, FI (2013) GIS-Based Production Of Digital Soil Map For Nigeria Ethiopian Journal of Environmental Studies and Management 6(5):498-506Available at http://dx.doi.org/10.4314/ejesm.v6i5.7[Accessed 30, June 2018]

Nonguierma, A (2011). Geospatial for SocioEconomic Development in Africa United Nations Economic Commission for Africa. Africa Geospatial Forum 2011 Nairobi, Kenya - 6-8 September 2011.

Odeh, IOA; Leenaars, J; Hartemink, A; Amapu, I (2012). The challenges of collating legacy data for digital mapping of Nigerian soils. In: Digital Soil Assessments and Beyond-Minasny, Malone \&McBratney (Eds). Taylor\& Francis Group, London, ISBN 978-0-415-62155-7 p.453-458

Ogunbadewa, EY (2012). Developing natural resources database with Nigeriasat-1 satellite data and geographical information systems. The Egyptian Journal of Remote Sensing and Space Sciences 15: 207-214

Ogunkunle, AO (2003). Spatial variability of some chemical properties in two Ultisols mapping units in Southern Nigeria. Soil Survey and Land Evaluation 6: 26-32

Okeke, FI; Nkwunonwo, UC (2007). Production of a Digital Soil Map/ Database for Nigeria. The Nigerian Journal of Space Research, 4: 37-48

Pásztor, L; Szabó, J; Bakacsi, Z; Laborczi, A (2012). Elaboration and applications of spatial soil information systems and digital soil mapping at Research Institute for Soil Science and Agricultural Chemistry of the Hungarian Academy of Sciences. https://doi.org/10.1080/10106049.2012.685895

Pourabbas, E (Ed.). (2014). Geographical Information Systems: Trends and Technologies. CRC Press, Taylor \& Francis Group, Boca Raton, FL

Pretorius, D (2013). New GIS tools and geospatial data sets for surveying and mapping Information from SMC-Synergy. PositionIT September 2013, p33-34

Rossiter, DG (2008). Digital Soil Mapping as a Component of Data Renewal for Areas with Sparse Soil Data Infrastructures. In: A.E. Hartemink, A. McBratney\& M.L. MendonçaSantos (Editors), Digital Soil Mapping with Limited Data. Springer, pp. 69-80.

Santos, WJR ; Silva, BM; Oliveira, GC ;Volpato, MML ; Lima, JM ;Curi, N ; Marques, JJ (2014). Soil moisture in the root zone and its relation to plant vigor assessed by remote sensing at management scale. Geoderma, 221: 91-95

Schirrmann, M; Gebbers, R; Kramer, E (2013). Performance of automated near-infrared reflectance spectrometry for continuous in situ mapping of soil fertility at field scale. Vadose Zone J. 12. doi:10.2136/vzj2012.0199. Soil Science Society of America

Scull, P; Frankling, J; Chadwick, OA; McArthur, D (2003). Predictive soil mapping: A review. Prog. Phys. Geogr. 27:171-197.

Siakeu J; Oguchi T. (2000) Soil erosion analysis and modelling: a review. Transactions of the Japanese Geomorphological Union, 21 (4), 413429

Singh R.K., Aggarwal S.P., Turdukulov U., Hariprasad V (2002) Prioritization of Beta river basin using Remote Sensing \& GIS technique. Indian Journal of Soil Conservation. 30 (3) 200205.

Singh, R; Oza, S; Chaudhari, K; Dadhwal, V (2005). Spatial and temporal patterns of surface soil moisture over India estimated using surface wetness index from SSM/I microwave radiometer. International Journal of Remote Sensing, 26(6): 1269-1276.

Sonneveld, BGJS (1996). Compilation of a soil map for Nigeria: a nation-wide soil resource and land form inventory In: Proceedings of the thirteenth West and Central African Soil Correlation SubCommittee Meeting, Kumasi, Ghana, 11-15 November 1996.

Ugbaje, SU; Reuter, HI (2013). Functional digital soil mapping for the prediction of available water capacity in Nigeria using legacy data. Vadose Zone J. 12. doi:10.2136/vzj2013.07.0140 
knowledge, and fuzzy logic, Soil Science Society

Umar, M; Munir, S; Ali, I; Qureshi, S; Notarnicola, C; Rahman, S; Weng, Q (2017). Soil Moisture Using Optical Remote Sensing and Ground Measurements: A Case Study from Pakistan. In Weng, Q. (Ed). Remote Sensing Applications Series: Remote Sensing for Sustainability, Taylor $\&$ Francis Group. Boca Raton, FL

Van Lynden, GWJ; Mantel, S (2001). The role of GIS and remote sensing in land degradation assessment and conservation mapping: some user experiences and expectations. International Journal of Applied Earth Observation and Geoinformation 2001 (1):61-68.

Vereecken, H; Huisman, J; Pachepsky, Y; Montzka, C; Van Der Kruk, J; Bogena, H; Weihermüller, L; Herbst, M; Martinez, G; Vanderborght, J (2014). On the spatiotemporal dynamics of soil moisture at the field scale. J. Hydrology. 516: 76-96.

Werban, U; Bartholomeus, H; Dietrich, P; Grandjean, G; Zacharias, S (2013). Digital Soil Mapping: Approaches to Integrate Sensing Techniques to the Prediction of Key Soil Properties. Vadose Zone J. doi:10.2136/vzj2013.10.0178. Soil Science Society of America. Open access

Zhu, AX; Hudson, B; Burt, J; Lubich, K; Simonson, D (2001). Soil mapping using GIS, expert 